\title{
Migraine attacks triggered by mild head trauma, and their relation to certain post-traumatic disorders of childhood
}

\author{
DAVID C. HAAS AND ROBERT D. SOVNER \\ From the Department of Neurology, Upstate Medical Center, \\ State University of New York, Syracuse, N.Y., U.S.A.
}

This paper reports five cases who repeatedly had migraine attacks triggered by mild head trauma. All the cases had some of the various neurological manifestations of migraine as a part of the attacks, and in three cases these manifestations generally occurred without headache. Although there are reports about patients beginning their 'career' in migraine after suffering head trauma (Michael and Williams, 1952; Müller, 1955; Burke and Peters, 1956; Barolin, 1966), there are no reports about patients having individual migraine attacks minutes or hours after a blow to the head. However, Whitty, in his paper 'Migraine without headache' (1967), mentioned the past history of a 50-year-old man (case 6) who "when an amateur boxer . . . had had attacks of numbness and weakness of the left side lasting one half to one hour and associated with throbbing headaches after fights in which he received punishment to head. They ceased when he gave up boxing'. We believe such cases are more unrecognized than rare, and hope that this report will stimulate more general recognition of their occurrence. If a patient should present at the emergency room with the history of sudden onset of hemiplegia occurring shortly after a blow to the head, how many physicians would consider the diagnosis of migraine?

There are a few reports in the literature of blindness and other neurological symptoms and signs occurring in children shortly after mild head trauma (Pickles, 1949; Bodian, 1964; Griffith and Dodge, 1968). The pathogenesis of these episodes has been most uncertain. We see sufficient clinical similarity between these episodes and the post-traumatic episodes in our five migraine patients to suggest a pathogenesis common to both groups. We will present a sixth patient who helps link our migraine cases with the reported post-traumatic childhood cases by sharing symptoms and signs of both entities.
CASE REPORTS

\section{FAMILY A}

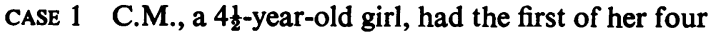
attacks in January 1967 at age 21 . The mother said the child fell off a couch, hitting the back of her head. She cried immediately. About $\mathbf{3 0}$ minutes later she became drowsy and irritable and had difficulty in standing. Her left leg 'was like rubber'. She was then brought to a local emergency room, where examination by a house officer showed that she 'favoured her right leg' and was reluctant to stand. Skull films were negative. She vomited in the emergency room and continued vomiting periodically until some 12 hours later, when she fell asleep for the night. The next morning she was well.

One week later, she and another child bumped heads while playing. She began to whine and cry. Fifteen minutes later she became drowsy. Her speech was slurred, her left leg 'was like rubber', and her left arm hung limply at her side. Within five hours she became alert and her signs cleared.

The third attack occurred in February 1967, 15 minutes after falling down some stairs. She got drowsy and lost control of her left side; three hours later she was well.

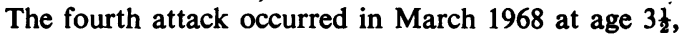
about 30 minutes after falling on the stairs and bumping her head (the mother did not think the child was stunned by the blow). She began to vomit and became sluggish, dysarthric, ataxic in her gait, and clumsy with her hands. Later in the day she became more alert and stopped vomiting. The next day one of us (D.C.H.) examined her. She looked alert. She hardly spoke, so that her dysarthria could not be evaluated-she might have been aphasic. She walked only with support. Her steps were quite ataxic. She reached clumsily for objects. Power was probably normal. Stretch reflexes were brisk and plantar responses equivocal. Sensation was grossly intact. Cranial nerves were unremarkable. She began walking unaided five days after the onset of the attack, but her gait did not return to normal for several more days.

An EEG taken on the second day of the attack was mildy abnormal because of excessive slow activity, which predominated posteriorly. An EEG five months later was normal. 
This child has a striking family history of migraine and of attacks similar to her own (See Fig. 1 and cases 2 and 3).

CASE 2 P.M., the 24-year-old mother of case 1, has had six neurological attacks, of which four were triggered by head trauma. The first occurred in 1953 at age 8, when she bumped her head and became drowsy and nauseated. She recalls being unable to walk and having slurred speech. She did not completely recover for a month. The next episode was seven years later, at age 15 . On the way to church she fell on the ice and hit her head. Two hours later she was carried out from service drowsy and 'acting wild'. A year later she had her third attack after colliding and bumping heads with a friend. About 15 minutes later she lost control of her left side. This lasted overnight. The fourth attack occurred spontaneously during a pregnancy at age 19 . She felt 'funny', could not speak, had numb arms, and lost control of her legs. The fifth episode was triggered by a blow to the back of the head. She developed slurred speech and weak legs.

The sixth and most severe attack occurred spontaneously in January 1968. Soon after noticing numbness in her left arm, she felt 'funny', in that 'people looked like they were in a different world'. Her speech became garbled. For the next two days she had severe headache and stayed at home sleeping most of the time. She was then hospitalized after collapsing in her bathroom. The sketchy hospital notes indicate that she was slightly febrile, lethargic, and had marked nuchal rigidity. Cerebrospinal fluid was normal. She was discharged feeling quite well 10 days after admission, but was unsteady on her feet for another week.

Some time after her first attack she began having headaches. In her adolescence she had about one head- ache a month when she was over-tired. At present, headaches occur once or twice a month and are usually premenstrual. They are throbbing and frontal and associated with nausea, vomiting, and photophobia.

CASE 3 B.H., a $5 \frac{1}{2}$-year-old girl, and first cousin of case 2, had her first attack at age 10 months when she fell and bumped her head on the rail of her crib. Within 20 minutes she began to act 'groggy and sleepy', and she vomited several times in the next two hours. Three hours later she was all right. In the next two years she had about 10 similar attacks, each one triggered by a bump on the head. These attacks increased in both intensity and duration, finally lasting six to seven hours. The mother observed that her daughter did not always 'choose the right word' and that 'her eyes looked vague' during these attacks.

Her most severe attack began one evening in July 1967 when she was 3 years 10 months old. While gathering wood for a fire, she tripped and fell, striking her head on the ground. She got up immediately and continued her chore. About 30 minutes later her father found her asleep on a couch. She slept for one and a half hours, and upon wakening began to vomit. At this time she was lethargic and did not seem to hear what was said to her. The vomiting ceased late at night and she then fell asleep. The next morning she was 'in a fog' and she slept intermittently most of the day. She had a low grade fever and did not eat. By the next day she walked very unsteadily. Four days after the onset of symptoms, she was admitted to University Hospital, lethargic, mute, uncooperative, and slightly febrile. By the next day, when seen by one of us (D.C.H.), improvement had begun. Neurological examination showed the following. She was fairly alert but was mute and not able to follow commands. She had a mild right

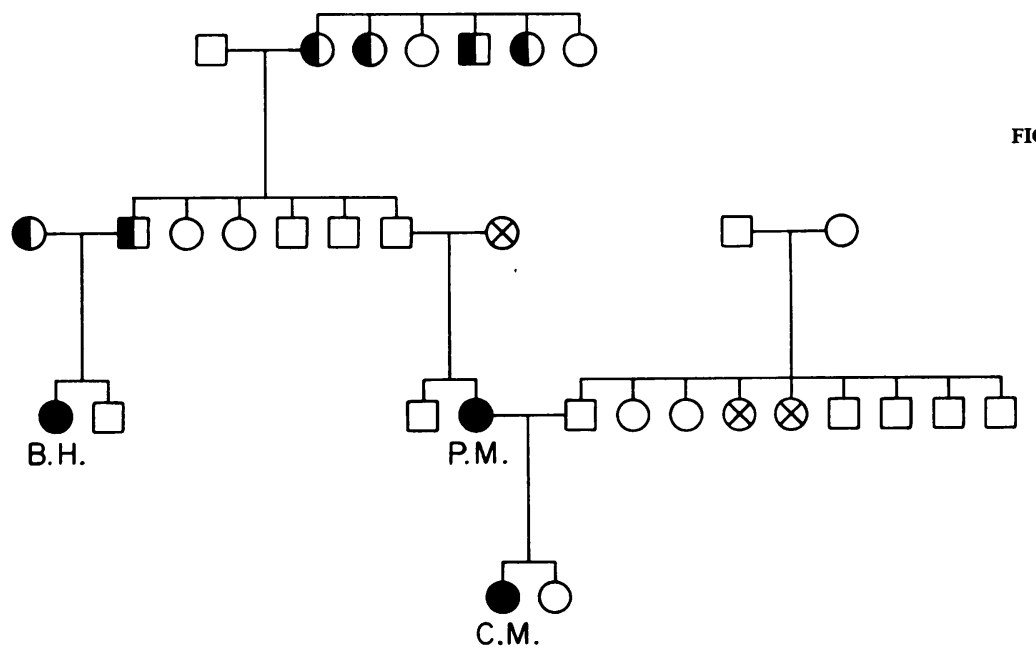

FIG. 1 Family tree of family $A$.

\footnotetext{
Migraine with neurological phenomena triggered by head trauma.

D. Migraine with neurological phenomena.

$\otimes$ Migraine headaches.
} 
hemiparesis with slightly brisker right-sided stretch reflexes. Plantar responses were flexor. Cranial nerves were normal. There were no cranial bruits. Lumbar puncture showed normal pressure; protein and cells were normal. Skull films were normal two days before admission. Electroencephalogram on the third hospital day was very abnormal. All left-sided leads showed continuous, moderately high voltage, and sometimes bursty, slow activity in the delta range. Right-sided leads had a slight excess of slow activity. She gradually improved during her hospitalization, and by the time of her discharge, one week after admission, she was walking and speaking very well. However, for the next two months she was often unable to choose the right word.

Since her discharge she has had five more attacks similar to those before her hospitalization, but with the addition of headache. The first occurred in February 1968 after a mild bump on the head. The second occurred in April 1968 after bumping her head on a table. She complained of headache but had no definite neurological symptoms. The third attack was in June 1968, at the age of 4 years 9 months. She tripped at the top of the stairs and banged her ribs after clutching the bannister. We do not know whether she bumped her head. Three hours later she complained of a headache. Her left arm became numb and 'things looked crooked'. One hour later she vomited. She soon went to sleep, but the next day still had a headache. The fourth attack was in February 1969 at age 5 years 4 months when she slipped and bumped her forehead on the ground. Within $\mathbf{3 0}$ minutes she began to vomit. For about 11 hours she complained of headache and vomited intermittently. The last episode occurred spontaneously in April 1969. The patient noted her right foot was asleep. This sensation soon spread to her right hand and face. An hour later she got headache and nausea. Five hours later she recovered.

The patient's 36-year-old mother has had occasional occipital headaches since age 9, generally when she is fatigued. They are preceded by an aura consisting of paraesthesiae in the left hand and a visual sensation that things are 'under water'.

The patient's 41-year-old father has had frequent migraine attacks since age 18 . The attacks begin with numbness in either hand and 'keyhole' vision. The numbness spreads to involve the ipsilateral leg and face. This aura fades in an hour when unilateral temporal headache begins. Nausea and vomiting accompany the headache which lasts for several hours. Several months before the onset of his attacks he fell off his bicycle sustaining a head injury of unknown severity. He arrived comatose at the hospital. A day or so later when his coma lightened, a right hemiparesis was detected. He fully recovered 16 days after his admission.

In 1954 , at age 26 , he developed a severe nauseating headache with drowsiness, fever and left hemiparaesthesiae. Three days later he was admitted to the hospital where left hemiparesis, left homonomous hemianopsia, and mental sluggishness were noted. Three days after admission a right parietal burr hole and ventriculogram were done, because of lack of clinical improvement. No superficial haematoma was found. The ventriculogram showed a $12 \mathrm{~mm}$ shift of the ventricular system to the left and a tipping of the caudal portion of the third ventricle to the left. No specific therapy was undertaken and the patient made a full recovery 12 days after his admission.

The paternal grandmother has had attacks of hemiplegic migraine since the age of 12 . She states that her first attack immediately followed mild head trauma, although all subsequent attacks were spontaneous. Three of her sisters and one brother are said to have had a similar history.

\section{FAMILY B}

CASE 4 R.G., a 19-year-old man, has had four migraine attacks. The first was at age 12. On Saturday afternoon he had been briefly stunned by a blow to the head while playing football. On Sunday morning he awoke with a mild headache. One hour later he got paraesthesiae in his left hand, forearm and arm. All symptoms faded shortly.

The second attack was in June 1967 at age 17. He recalls being hit on the head and believes that the trauma was related to the attack, but the temporal relationship between the two has slipped his mind.

The third attack was in March 1968 at age 18. At about 1.15 a.m. he was hit forcefully on the lip in a fistfight and was momentarily stunned. At about 3 a.m., while sitting in a car, he noted numbness in the tips of his left fingers. This sensation quickly ascended to involve the entire left upper limb and the left side of his lips, tongue, and nose. At the same time, he developed a severe right supraorbitaß headache with nausea. The numbness faded in an houg and he slept off the headache.

The fourth attack was on 20 April 1969 at age 19. At 11 a.m. he carelessly struck his head against the arm of aO couch and was momentarily stunned. At 12 noon a righe supraorbital headache began and soon was severe. Lateb nausea and vomiting occurred. At 1 p.m. numbness began? in his left finger tips and soon spread to involve his entire left upper limb and the left side of his lips, tongue, and nose. His left hand became clumsy and he had trouble in writing (he is left-handed). He lost left-sided vision. The numbness and hemianopia faded away in several hours, but the headache lasted some 12 hours. Neurological examination just after the end of the headache showed slight clumsiness of fine movements of the left hand and slight rotary-horizontal nystagmus on lateral gaze. The next day the examination by one of us (D.C.H.) was normal.

CASE 5 D.G., the 46-year-old father of R.G., stated that throughout his childhood he was subject to attacks of visual alteration and headache after bumping his head. Attacks occurred probably two to three times a year. No spontaneous attacks occurred. The first attack was at age 7 or 8 , the last was in his teens. The first symptom of the attacks was 'visual blurring', which began almost immediately after the blow to the head or jaw. He recalls this his peripheral vision was especially blurred, so that he had an effect similar to looking through a 'keyhole'. A mild dizzy sensation was generally part of the attacks. Severe headache with nausea and vomiting began soon after the visual disturbance and lasted overnight. His vision cleared in several hours. 


\section{FAMILY C}

CASE 6 J.S., a 6-year-old boy, was sleigh riding in January 1969 when his sleigh hit a post. He ran into the house crying but was quickly soothed by his mother, who noted a bruise mark on his left mastoid and jaw area. After drying his eyes, he went outside again, but did not play actively. About five to 10 minutes later, he came back into the house looking 'pouty'. He then began crying and responded to his mother's inquiries only by saying the word 'nothing'. His mother made him lie down and he slept for 30 minutes. When he awoke he looked heavily sedated and did not speak, except to say 'huh?' when spoken to. He could not stand, because his legs buckled under him. His eyes did not seem to focus and could not follow the mother's finger (the mother wondered whether he could see). Recovery began on the way to the paediatrician's office about four hours after the injury. The physician noted that the child was drowsy and limp, but was able to stand. Speech was slow and slurred. He sent the child to the emergency room at University Hospital where mild ataxia of gait and truncal ataxia were noted by a neurosurgical consultant. Complete recovery soon occurred.

The child has had three previous minor attacks after mild head trauma. All followed a fall out of bed. The second, which was the most definite, consisted of vomiting and headache lasting several hours. The symptoms began about 15 minutes after the fall from bed.

The 30-year-old father has had two severe headaches. The first, in 1961, lasted about 12 hours, and was associated with nausea, vomiting, difficulty in speaking, and clumsiness of the hands. The second headache, in April 1964, was similar, but milder. One of the father's brothers has also had two headaches with nausea, vomiting, difficulty in speaking, and clumsiness of the hands.

\section{DISCUSSION}

We firmly believe that the post-traumatic attacks in our cases 1 through 5 were typically migrainous except for their having been triggered by a blow to the head. Certainly the temporary paraesthesiae, hemipareses, visual disturbances, etc., of our cases are the sort of neurological phenomena that occasionally precede or accompany migraine headaches. And the sick headaches that three of the five cases (cases 2, 4, and 5) had during attacks were the sort one generally labels as migrainous. Although case 1 has never had headaches with attacks, and cases 2 and 3 had some attacks without headache, the diagnosis of migraine is not necessarily weakened. Wolff (1963a) and Whitty (1967), among others, have shown that migrainous patients can have neurological attacks without headache. The spontaneous attacks of cases 2 and 3 were like those triggered by trauma, and in themselves seem typically migrainous. Only case 2 has had spontaneous headaches of any importance. The fact that they are throbbing and associated with vomiting and photophobia speaks strongly for their being migrainous. The history of migraine headaches and migraine with neurological phenomena in family A reinforces the diagnosis of migraine attacks in cases 1,2 and 3 .

Case 6 is more difficult to label as migrainous, because he has only had a single neurological episode after head trauma, and an attack of nausea and vomiting beginning 15 minutes after falling out of bed, and two other brief, ill-defined dazed episodes after falling out of bed. Also, he does not have a strong family history of migraine or similar neurological episodes. However, his neurological attack was quite consistent with migraine, especially basilar artery migraine (Bickerstaff, 1961), because of his apparent difficulty in seeing, his dysarthria, and his cerebellar ataxia, during his neurological episode. His neurological manifestations were also quite similar to some of those in cases 1, 2, and 3, whose attacks are more clearly migrainous, as discussed above. Although he does not have a strong family history of migraine, his father and paternal uncle have had two severe headaches with nausea, vomiting, difficulty in speaking, and clumsiness of the hands.

The single post-traumatic episode of case 6 , and the various post-traumatic episodes of all our other cases, if looked at as isolated incidents and without their family history of migraine, are strikingly similar to the baffling temporary post-traumatic neurological disorders of childhood as described in the literature. For a long time, physicians have recognized that minor head trauma will occasionally induce various temporary, yet sometimes severe or even alarming, neurological disturbances. These have almost always been described in children, and often occur minutes or even hours after the trauma. The earliest reports of this condition of which we are aware are those of Walton and Brooks (1897) and Walton (1898). Walton's second case, as paraphrased by the neurosurgeon Pickles (1949), 'concerned a $3 \frac{1}{2}$-year-old girl who was thrown to the floor from a small swing and struck her head. She was dazed and later vomited. On the following day, she had paralysis of the left arm, and exploration of the head was advised. Overcrowding of the hospital caused a delay of 12 hours, by which time she seemed much better and was beginning to use the left hand, so that no operation was done. Her convalescence was rapid, and she made a quick and complete recovery ...'

In 1943 Pickles (1949) attended a 21-year-old boy who had a post-traumatic attack similar to Walton's case, described above. The child 'fell from his highchair with such force that his head bounced on the floor. He seemed dazed for a moment or two but had no definite period of unconsciousness. He cried loudly for a few minutes, as one might expect, but 
soon seemed to forget all about the fall ... He ate his supper ... and was put to bed. Two hours later he began to vomit; he was very pale and his skin was moist and cold, and he was very drowsy, with occasional convulsive twitchings of the right arm and leg. His mother, who is a nurse, believed that he had a severe head injury, so he was taken at once to the hospital. On arrival he was found to be in shock ... . ; he was semicomatose and had greatly depressed reflexes and motor power of the right arm and leg ... . Treatment for traumatic shock was started, and preparations for cranial exploration were got under way. At about the time when these were completed, his condition began to improve ... In four hours he was so much better that it was evident that exploration would not be needed, and by the next morning, some 16 hours after the injury, he was fully conscious and happy, with no evident neurological abnormality.'

Since Pickles's 1949 report, only two other papers have reported neurological attacks after mild head trauma. Bodian (1964) reported six cases of temporary blindness in children. Only one of his six children was unconscious (two minutes) after the injury; the others were simply stunned. Four became blind immediately, three totally, and one in the right eye alone. The other two became blind within a few minutes. Two had dilated and fixed pupils and another had sluggish pupils. All recovered within 12 hours. All the children had headache, nausea and vomiting, and drowsiness in various combinations.

Griffith and Dodge (1968) reported seven similar cases in children. The onset of blindness ranged from immediate to 20 minutes after the blow. Most of the children had associated vomiting. Their case 2 is a good example of the syndrome: 'A 6-year-old boy fell from his bicycle, striking the back of his head. He got up immediately and ran into the house complaining only that his head hurt. Shortly thereafter he said that he could not see well. He then took a brief nap and on awakening was very restless and apparently blind. When examined in the emergency room . . . three hours later, he was extremely agitated ... He claimed that he could not see... The pupils responded briskly to light. The rest of the examination was unremarkable. An electroencephalogram was obtained within an hour of entry into the hospital. During this test he slept briefly, and on awakening, readily recognized his parents and identified colours and pictures in a manner indicating normal visual acuity.'

There are obvious similarities between our cases and the literature's post-traumatic cases. Most obviously, all cases had temporary central nervous system phenomena triggered by mild head trauma. All were children or adolescents. Many attacks did not occur immediately after the blow, but followed at an interval of minutes to hours. Vomiting and drowsiness were an almost constant feature of the episodes.

There are also noteworthy differences between our ${ }_{0}$ cases and those in the literature. Our cases had repeated attacks, whereas no case in the literature had $\frac{5}{\sqrt{0}}$ more than one. All our cases (except case 6) have a family history of similar attacks, while the literature's cases have not. All our cases have a family history of migraine headaches, or at least of severe headaches with nausea and vomiting. Although none of our cases had clear-cut attacks of blindness, two (cases 5 and 6) had definite visual disturbances: keyhole vision in case 5 , and inability to focus and possible blindness in case 6 .

The similarities between our cases and the literature's post-traumatic cases are enough to suggest a pathogenesis common to both groups. Our cases are much more prone to get attacks after head trauma; we suggest that this heightened susceptibility is related to their genetic endowment, which also manifests itself in some of our cases and their relatives as migraine headaches and migrainouso neurological phenomena. Although migraine is $\infty$ difficult to define, any current definition woul\$ 옥 certainly be strained by calling the post-traumati $\vec{Q} \overrightarrow{.}$ attacks in the literature 'migraine'. Nevertheless, wए believe that the physiological and chemical disturb $b_{\overparen{D}}$ ances underlying them may be similar to those ip migraine.

We think cerebral arterial spasm is the initial event in the post-traumatic attacks in our cases and the literature's cases. We suggest that the spasm is induced by sudden traction on the arteries at the base of the brain, resulting from momentary brain displacement at the time of the head trauma (see Dott, 1960). To support this idea there is both clinical evidence from neurosurgery in man and experimental evidence in various animals, including primates, that the arteries of the circle of Willis, the major cerebral arteries, and also the basilar and vertebral arteries, may go into reversible spasm if they are retracted, stroked, or pinched (Pool, Jacobson, and Fletcher, 1958; Corday, Rothenberg, and Irving, 1963; Echlin, 1965; Symon, 1967a, b). There is no conclusive experimental evidence in animals that a blow to the head can produce such cerebral arterial spasm. However, Echlin (1965) has observed localized spasm, in the absence of subarachnoid haemorrhage, in the basilar or vertebral arteries (the ones he studied) after 'concussive blows' to heads of monkeys. He believed the spasm was probably due to the trauma rather than to associated factors. We have found only one report of arterial spasm occurring in man after head trauma (Freiden- 
felt and Sundström, 1963). These authors angiographically demonstrated spasm of the intracranial carotid artery and middle and anterior cerebral arteries in various combinations in five post-traumatic cases. The first three cases had other possible causes for the spasm: subarachnoid haemorrhage, extracerebral haematoma, and an 'expansive process in the frontal region'. The fourth and fifth cases had prolonged arterial spasm, apparently due to head trauma alone. The severity of the trauma is not given. Both patients were left with permanent, severe neurological deficits.

Our case 5 and the post-traumatic cases in the literature, whose neurological symptoms began immediately after head trauma, can be conceived as having had immediate cerebral arterial spasm, severe enough to produce marked focal ischaemia with its resultant hypoxia and disturbance of cerebral function. What can we conceive for those cases-our cases 1 and 3, and some of the cases of Griffith and Dodge, for example-whose symptoms began in the neighbourhood of several to 30 minutes after the injury? We see two main possibilities. First, arterial spasm might take this amount of time to develop sufficient intensity to cause focal cerebral hypoxia. Some evidence for this can be taken from Symon's experimental study of cerebral arterial spasm in baboons (1967b). He showed that after pinching, the average time for the proximal middle cerebral artery to reach its maximal spasm was 3.8 minutes (S.D. $\pm 1 \cdot 5)$. The second possibility is that the arterial spasm might be insufficiently intense to result in symptomatic focal cerebral hypoxia but might, by decreasing blood flow, induce a reactive hyperaemia, leading to cerebral oedema and impaired brain function. This explanation fits especially well when the latency between the trauma and the onset of neurological symptoms is several hours or so, for we have difficulty in imagining that arterial spasm severe enough to cause ischaemic hypoxia can begin several hours after an injury.

The work of Sicuteri and his colleagues (1967), in particular, prompts us to suggest some possible pathological mechanisms after arterial spasm. Platelet aggregation occurs when blood flow decreases, and the platelets then release 5-hydroxytryptamine (serotonin). 5-Hydroxytryptamine, itself a dilator of the micro-circulation, induces the release of vasoactive polypeptides (kinins) from plasma. Together these substances, and probably others as well, cause increased capillary permeability and cerebral oedema.

We believe that our patients are inordinately sensitive to traumatic cerebral arterial spasm and perhaps to its sequelae as well, in part due to their genetic predisposition for migraine. Since arterial spasm may be the first event in the sequence of a migraine attack (Wolff, 1963b), we think that any stimulus tending to induce arterial spasm could precipitate an attack in a susceptible person.

In addition to the disorders described above, there is a more common syndrome that follows mild head trauma in children (Schnitker, 1949; Pudenz, Todd, and Shelden, 1961; Mealy, 1968). Mealy, in his textbook, Pediatric Head Injuries, says this about the syndrome: 'In younger children, who were not unconscious immediately after the blow or only dazed momentarily, the triad of excessive somnolence or lethargy, irritability and vomiting is characteristic. The onset of these symptoms may be delayed for an hour or more after an initial period of well-being. Often these children will not talk, tend to withdraw from the examiner, and merely cry when disturbed. When not aroused they promply drift off into a sleep-like state. They either remain listless in any position they are placed or lie curled up on their sides. This pattern of response to head trauma is sufficiently stereotyped and seen often enough to be considered a definite syndrome representative of concussion in infants and young children.'

This syndrome shares the somnolence, irritability, vomiting, and frequent delay of onset with the posttraumatic attacks of our cases and the cases we described from the literature. If this syndrome had associated focal neurological signs, it would be no different from the other post-traumatic cases. Therefore, we suspect this syndrome is closely related to them; the differences between it and the others may simply reflect the degree and locus of brain involvement. This relationship is strengthened by our case 3 having had attacks just like the more common ones described above by Mealy before she had attacks with associated focal neurological symptoms and signs.

Little attention has been given to traumatic cerebral arterial spasm in the past, judging from the paucity of reports in the literature. We feel that its role in concussion and severe head injury, as well as in the post-traumatic disorders discussed above, needs to be more thoroughly investigated.

\section{SUMMARY}

We report six cases who had migrainous neurological attacks triggered by mild head trauma. The first five had multiple attacks triggered in this way, while the sixth had only a single attack. To our knowledge, there have been no previous reports of such a condition. These cases are analysed in relation to those disorders in childhood that follow mild head trauma. Traumatic cerebral arterial spasm is postulated as the initial event in the attacks of our 
cases, as well as in the attacks of the other posttraumatic cases in the literature.

We wish to thank Dr. Herbert Lourie of the Neurosurgery Department for his helpful counsel and for bringing case 6 to our attention. We also thank Dr. Sulaiman, resident in neurology, for referring case 4 to us.

\section{REFERENCES}

Barolin, G. S. (1966). Migräne und andere paroxysmale Hirndurchblutungsstörungen nach Kopftraumen. Wien med. Wschn., 116, 462-468.

Bickerstaff, E. R. (1961). Basilar artery migraine. Lancet, 1, 15-17.

Bodian, M. (1964). Transient loss of vision following head trauma. N.Y. St. J. Med., 64, 916-920.

Burke, E. C., and Peters, G. A. (1956). Migraine in childhood. Amer. J. Dis. Child., 92, 330-336.

Corday, E., Rothenberg, S. F., and Irving, D. W. (1963). Cerebral angiospasm, a cause of the cerebral stroke. Amer. J. Cardiol., 11, 66-71.

Dott, N. M. (1960). Brain, movement and time. Brit. med. J., 2, 12-16.

Echlin, F. A. (1965). Spasm of basilar and vertebral arteries caused by experimental subarachnoid hemorrhage. J. Neurosurg., 23, 1-11.

Freidenfelt, H., and Sundström, R. (1963). Local and general spasm in the internal carotid system following trauma. Acta radiol. Diagn. (Stockh.), 1, 278-283.

Griffith, J. F., and Dodge, P. R. (1968). Transient blindness following head injury in children. New Engl. J. Med., 278, 648-651.

Mealy, J., Jr. (1968). Pediatric Head Injuries, pp. 56-57. Thomas: Springfield, Ill.
Michael, M. I., and Williams, J. M. (1952). Migraine in children. J. Pediat., 41, 18-24.

Müller, E. (1955). Gibt es eine sogenannte traumatische Migräne? Mschr. Unfallheilk., 58, 143-148.

Pickles, W. (1949). Acute focal edema of the brain in children with head injuries. New Engl. J. Med., 240, 92-95.

Pool, J. L., Jacobson, S., and Fletcher, T. A. (1958). Cerebral vasospasm-clinical and experimental evidence. J. Amer. med. Ass., 167, 1599-1601.

Pudenz, R. H., Todd, E. M., and Shelden, C. H. (1961). Head injuries in infants and young children. Calif. Med., 94, 66-71.

Schnitker, M. T. (1949). A syndrome of cerebral concussion in children J. Pediat., 35, 557-560.

Sicuteri, F. (1967). Vasoneuroactive substances and their implication in vascular pain, pp. 6-45 in Research and Clinical Studies in Headache, Vol. I. Edited by A. P. Friedman. Williams and Wilkins: Baltimore, Md.

Symon, L. (1967a). Vascular spasm in the cerebral circulation, pp 78-95 in Background to Migraine: 1st Migraine Symposium, 1966. Edited by R. Smith. Heinemann: London.

(1967b). An experimental study of traumatic cerebral vascular spasm. J. Neurol. Neurosurg. Psychiat., 30, 497-505.

Walton, G. L. (1898). Subarachnoid serous exudation productive of pressure symptoms after head injuries. Amer. J. med. Sci., 116, 267-275.

_- , and Brooks, W. A. Jr. (1897). Observations on brain surgery suggested by case of multiple cerebral hemorrhage. Boston med. Surg. J., 136, 301-305.

Whitty, C. W. M. (1967). Migraine without headache. Lancet, 2 , 283-285.

Wolff, H. G. (1963a). Headache and Other Head Pain, 2nd edn., p. 233 Oxford University Press: New York.

- (1963b). Headache and Other Head Pain, 2nd edn. pp. 234-241 Oxford University Press: New York. 